\title{
PARA UNA REVISIÓN DE LA POLÉMICA MEXICANA DIECIOCHESCA CON MANUEL MARTÍ, DEÁN DE ALICANTE ${ }^{1}$.
}

\author{
José Carlos ROVIRA \\ Universidad de Alicante \\ ...admirador del deán de Alicante Manuel Martí \\ -tan célebre en su tiempo y tan olvidado en el nuestro-
}

Miquel Batllori.

La fortuna cultural que tuvo el deán de Alicante Manuel Martf, tutulo eclesiástico y urbano con el que aparecerá citado sistemáticamente por sus contemporáneos, ha decrecido hasta el límite de que en la actualidad sólo se reedita su contribución a la escatología imprescindible, la Oratio pro crepitu ventris ${ }^{2}$, una broma fisiológica de un personaje que tuvo en la ironía, en un mal genio congénito que asumía también formas de humor, en sus amplios conocimientos de latín y griego, en su condición central de humanista ${ }^{3}$ y en su rechazo del

${ }^{1}$ El presente artículo consiste en un conjunto de notas sobre un proceso de investigación que estoy desarrollando, para insistir en lo que considero esencial del método de aproximación a la literatura, o globalmente a la cultura hispanoamericana escrita durante la Colonia: sólo una atención rigurosa al ámbito español, cuando enfocamos la literatura colonial, nos evitará descubrir atlánticos a estas alturas de nuestro siglo. En cualquier caso es un honor poder dedicar estas notas a la Dra. María Jesús Rubiera Mata, de cuyo rigor científico y sensibilidad cultural he tenido ocasión de aprender mucho estos últimos años.

2 Oratio pro crepitu ventris habita ad patres crepitantes ab Emanuele Martino, Ecclesiae Alonensis Decanus (En Clarorum Valentinorum...Orationes Selecta), Lausanne, 1767, págs 90-117. Las traducciones castellanas de la Defensa del Pedo se suceden desde la de Don Roque Valero Oquendo en 1776 (La oración que en Defensa de'l Pedo (pro crepitu ventris) compuso el Doctissimo y Célebre Don Manuel Martí. Traducida al el Castellano por D.R.V.O., Toledo, Nicolás de Almanzano, 1776).

${ }^{3}$ La reivindicación y el estudio riguroso de la figura de Martí ha tenido en los últimos años dos valedores principales: Antonio Mestre quien, en sus estudios 
mundo inculto que lo rodeaba, sus mejores exponentes, hasta el punto de provocar la atención de figuras europeas y la pasión intelectual de Gregorio Mayáns y Siscar, quien escribió su biografía y mantuvo una amplia correspondencia en lo que fueron los últimos 21 años alicantinos de quien siempre consideró su entorno próximo como un desierto cultural, encerrado en otro desierto más amplio como era España para Martí.

En el presente trabajo nos proponemos revisitar (y si es posible revisar) el ámbito de una polémica en la que Martí, fallecido en 1737, se vio envuelto en México a partir de que llegaran allí los volúmenes de su Epistolarum ${ }^{4}$, publicado dos años antes de su muerte. Aproximadamente la polémica se habría comenzado a generar hacia 1745 , y tuvo amplio desarrollo, como veremos. Las voces encontradas y seleccionadas insisten una y otra vez en desmontar las ideas del "deán de Alicante", con lo que esta ciudad, y su colegiata de San Nicolás, obtuvieron una continua presencia en Nueva España que no voy a enfocar como un hito de la historia local, sino, en el caso que nos ocupa, como una desafortunada intervención de su deán que estuvo en boca de las principales figuras del virreinato, y de algún otro punto de

sobre Mayáns, publica el amplio Epistolario Mayáns y Martí, Valencia, Publicaciones del Ayuntamiento de Oliva, 1973; y da una visión de la obra del mismo en "El deán de Alicante: entre la ilusión y la desesperanza", Humanismo y critica histórica en los ilustrados alicantinos, Universidad de Alicante, 1980, págs.14-42; y Luis Gil "El deán Martí o la esperanza fallida", en Tres grandes humanistas españoles, Madrid, Fundación Universitaria Española, 1975, págs. 6384; "Las 'notae in Theocritum' del deán Martí", Cuadernos de Filología Clásica, 11, 1976, págs. 19-52; "Los 'Apuntes autobiográficos' del deán Marti", Boletín de la Real Academia Española, LVIII, 1978, págs. 47-101; y, sobre todo, la edición y traducción de la biografía escrita por Mayáns, Emmanuelis Martini, Ecclesiae Alonensi Decani, Vita, Scriptore Gregorio Maiansio Generoso Valentino (Estudio preliminar, edición bilingüe y comentario de Luis Gil), Valencia, Publicaciones del Ayuntamiento de Oliva, 1977. Para el contexto de las ideas de Martí, con amplia referencia a ellas, no es necesario decir que son material obligado los libros de Antonio Mestre, Ilustración y reforma en la Iglesia. Pensamiento político-religioso de Don Gregorio Mayáns y Siscar (1699-1781), Valencia, Publicaciones del Ayuntamiento de Oliva, 1968; y de Luis Gil, Panorama social del humanismo español, Madrid, Alhambra, 1981.

${ }^{4}$ Epistolarum libri duodecim, Mantuae Carpetanorum, Joannem Stunnicam, 1735. 
América. Su fama, en negativo en el espacio estudiado, fue por tanto inmensa, y nos va a servir sobre todo para una relectura de los puntos principales de la polémica, en lo que conciernen al ámbito americano, abriendo algún apunte también hacia el ámbito español.

Se parte de una historia conocida que resumo ahora: en el libro VII, Carta XVI, del Epistolarum libri duodecim, del deán de Alicante Manuel Martí está la carta a Antonio Carrillo, cuyo título es "Emmanuel Martinus, Antonio Carrillo, egregiae indolis adolescenti, salutem et amorem (Manuel Martí desea amor y salud al joven de claras prendas Antonio Carrillo)". El objetivo de la carta era disuadir al destinatario de su idea de ir a estudiar a América, recomendándole Martí -había sido alli su formación principal- que dirigiese sus pasos hacia Roma, puesto que América -México concretamente- ni tenía maestros, ni Universidades que pudiesen considerarse tales, ni bibliotecas. La carta está fechada el 4 de Mayo de 1718.

El Epistolarum, publicado en 1735, produjo un efecto insospechado en Ciudad de México donde Juan José de Eguiara y Eguren, canónigo de la Catedral, respondió al texto de Martí con su Bibliotheca mexica$n a^{5}$, un trabajo del que se public6 una parte en 1755 , en el que polemiza con Martí y reconstruye la obra y el nombre de más de 2.000 escritores de México y América desde antes de la llegada de los españoles hasta el mundo literario de la colonia. De la totalidad del texto de Eguiara existe una edición reciente ${ }^{6}$.

Hasta aquí, los datos conocidos de la polémica, sobre los que intentamos plantear ahora una perspectiva que pueda ampliar e incluso modificar su enfoque.

${ }^{5}$ Bibliotheca mexicana, Mexici, Ex nova Typographia in Aedibus Authoris editioni, 1755. Se publicó el volumen I, correspondiente a las letras ABC. Eguiara pudo llegar hasta la letra J, encontrándose en la actualidad el material manuscrito en la Biblioteca de la Universidad de Austin (Texas). El mejor trabajo de conjunto sobre el autor es el de Agustín Millares Carlo, "Noticia biográfica y bibliografía de Don Juan José de Eguiara y Eguren", en Cuatro estudios biobibliográficos americanos, México, FCE, 1986, págs. 218-278.

- Juan José de Eguiara y Eguren, Bibliotheca mexicana (Texto latino y traducción), compilación, prólogo y notas de Ernesto de la Torre Villar, con la colaboración de Ramiro Navarro de Anda, México, UNAM, 1986/1990, 5 vol. 


\section{La epístola del deán Martí}

La carta, escrita en 1718 , comienza hablando de las virtudes que Martf ha conocido en el joven Antonio Carrillo, con quien se ha encontrado "in Menesthei Portu", esto es, en el Puerto de Santa María, adonde Martf estuvo a lo largo de varios meses en $1712^{7}$. A éste, ahora desde Roma, le confiesa que su conversación le ha proporcionado el máximo placer, y que su ingenio, soltura de palabra y modestia lo han cautivado aunque, sin embargo, cuando supo Marti que estaba a punto de embarcar hacia el Nuevo Mundo, tuvo gran preocupación:

Me preocupó sobremanera tu decisión, tomada, a mi entender, con poco acierto y con ningún provecho. Me había dado cuenta de tu valiosa forma de ser, $\mathrm{y}$ de tu carácter más propenso al estudio de las letras y las artes de Minerva que a las artimañas del comercio y a los engaños lucrativos. Así pues, me propuse muy activamente desbaratar ese propósito tan inapropiado, con gran esperanza en conseguirlo, pues tenia la impresión de que te habías lanzado a ese asunto poco resueltamente y con escasa reflexión, y que estabas aún con el ánimo suspenso.

Siguen una serie de consejos dedicados a que Carrillo asuma como objetivo el sacerdocio, puesto que será la garantía de una vida intelectual libre:

...apártate con aversión de una esposa que debes escoger y de unos hijos que debes educar. Piensa solamente en el sacerdocio. Siendo célibe, dispondrás en abundancia de todas las cosas placenteras de la vida. Especialmente la libertad y la tranquilidad, en las cuales juzgabas, verdadera e inteligentemente, que radica el caudal de la felicidad humana,

para retomar el objetivo central que ha motivado el escrito, ampliandolo a los peligros de la navegación y, luego, de la vida que puede llevar en el Nuevo Mundo:

7 "Anno XII elabentis saeculi pridie Nonas Januarias Hispali profectus ad portum Menestei", Vita Enmanuelis Martini, ed. cit, pág. 158. 


\begin{abstract}
¿Qué objeto tiene, me digo, esta nefasta navegación, tantos esfuerzos agotadores, tantos peligros que afrontar? [...] ¿Acaso deseas estas cosas intrascendentes e inútiles -ante las que está la gloria y el brillo de la riqueza-, para vivir opulentamente, sumirte en lujos, marchitarte enmedio de una inactividad enervante, entre borracheras y festines? Sin duda te propones esto. Eres un joven -tal como te me has mostrado en verdad- serio, frugal, moderado, trabajador y apasionado en el amor por las letras. Pero quizá vas allí para librarte de los estudios, bajo la instrucción y la disciplina de los indios. ¡Los mejores maestros, por Hércules!
\end{abstract}

La última frase nos introduce ya en lo que será el marco esencial de la polémica: América, tierra de indios y, por tanto, infructífera para la razón. La idea, sobre la que Martí insiste luego, es básica para entender la dinámica cultural en la que se está introduciendo $\mathrm{y}$, por supuesto, el sentido de la réplica de Eguiara. Insiste a partir de aquí en las razones morales y culturales que le deben impedir el viaje, a no ser que lo que quiera es acumular riquezas, aunque siempre ha pensado que es mejor vivir en ese término medio de riqueza que nos permite vivir en la razón, y no en el desenfreno. Por otra parte, la naturaleza le condicionará, entrando Mart́́ con esta afirmación en uno de los motivos centrales de una polémica esencial en el siglo, la de la naturaleza american $^{8}$, sobre la que volveremos luego:

Los instintos de la naturaleza se manifiestan y discurren espontáneamente. Entremos en razones. ¿Cómo es que vas a residir entre los indios, en un desierto de cultura tan vasto? ¿A quién acudirás, no diré ya a un maestro, con cuyos consejos puedas instruirte, sino simplemente a alguien que te escuche?: no diré a un sabio, sino a alguien deseoso de saber. Te lo diré más claro; alguien que no aborrezca las letras. ¿Qué libros consultarás? ¿Qué bibliotecas frecuentarás? Intentarás conseguir esto tan inútilmente como el que esquila a un burro o el que

${ }^{8}$ El libro esencial sobre la naturaleza de América y su debate originario sigue siendo el de Antonello Gerbi, La naturaleza de las Indias Nuevas, México, FCE, 1978; especial atención al debate en el pensamiento del siglo XVIII, dentro de una perspectiva más amplia que la de la naturaleza, hay en la obra del mismo autor La disputa del Nuevo Mundo (1750-1900), México, FCE, 1982 ( $2^{\mathrm{a}}$ ed.). Para el marco cultural del presente trabajo son obras imprescindibles. 
ordeña a un cabrón. ¡Ea! Retráctate de estas simplezas y regresa acá, donde puedas cultivar tu espíritu, encontrar un modo honesto de vida y hacerte acreedor de nuevos honores. A lo que tú responderás: ¿En qué lugar podemos conseguir esto? En Roma, te añado. Este es el lugar más adecuado a tu talento, tu ingenio y tu plan de vida...

La localización del lugar alternativo, le sirve a Martí para seguir dando consejos sobre la vida que en esta ciudad se debe hacer, porque de no cumplirla da lo mismo Roma o México, con lo que ha situado ya en su carta el lugar concreto del Nuevo Mundo al que Carrillo quería dirigirse y, al hacerlo, ha emplazado el nombre de México como ofensa que será así sentida en Nueva España:

...no te dirigirás a Roma para recorrer calles y plazas, para admirar la suntuosidad de los edificios, para llevar una vida baldía, para consumirte en reverencias y en otras ocupaciones de los meritorios. Pues con tales comportamientos, ¿qué más da que estés en Roma o en México?

Los consejos por la edad de Carrillo, quien tenía 26 años, se convierten en una reflexión última sobre sus estudios, puesto que está en la mejor edad para realizarlos, y en el convencimiento de que va a ser lo que le pide su decisión última. La carta de Martí nos ha entregado varias ideas sobre las que volveremos luego. Son las que impactarán fuertemente a los intelectuales de Nueva España. Una síntesis básica de lo principal habría que enunciarla hablando del desprecio al indio, a la naturaleza americana, a la incultura que Martí cree que reina en ella a pesar de los dos siglos de colonización, a que el Nuevo Mundo es tierra de negocios y no de ciencia, a que no hay ni bibliotecas, ni universidades, ni maestros, ni discrpulos...una síntesis de los elementos que como sabemos forman la polémica esencial de la Ilustración en América. Pero antes de adentrarnos en ella, será necesario acercarnos a la respuesta más contundente que obtuvo, la de Eguiara y Eguren. 


\section{La réplica de Eguiara y Eguren: valor central de la Bibliotheca mexicana en la configuración del siglo XVIII.}

El trabajo de traducción y edición de los 20 prólogos a la Bibliotheca mexicana que realizara en 1944 Agustín Millares Carlo ${ }^{9}$ permite en la actualidad un acercamiento amplio al objetivo cultural de Eguiara, y a los instrumentos con que se dotó para conseguirlo. Las 2.000 fichas de autores fueron un material esencial para el trabajo posterior de sucesivos bibliografos entre los que se cuentan Beristáin ${ }^{10}$, García Icazbalceta $^{11}$ y Toribio Medina $^{12}$. Los Anteloquia adquieren hoy en día un valor cultural que paso a describir sucintamente en las páginas que siguen ${ }^{13}$. El sentido central de ese valor procede no tanto de la condición de primer bibliógrafo, sino de la reflexión que antecede al volumen que de su obra consiguió publicar: los Anteloquia anticipan una forma de razón esencial para la cultura del siglo XVIII en Nueva España. Y anticipan, como veremos, muchas más cosas.

9 Juan José de Eguiara y Eguren, Prólogos a la Biblioteca Mexicana, Introducción y traducción de Agustín Millares Carlo, México, FCE, 1944.

10 José Mariano Beristáin de Souza (1756-1817) sucedió a Eguiara en el intento bibliográfico con su Biblioteca hispanoamericana septentrional, México (1816: 1 vol.) (1819: 2 vol) (1821: 3 vol.). Estudia ampliamente la figura de Beristáin, Millares Carlo en Cuatro estudios... cit. cap. "Don José Mariano Beristáin de Souza". Es interesante, porque muchos años después enlaza el bibliógrafo mexicano con una figura principal del ámbito preilustrado valenciano como Mayáns, tan determinante para nuestro deán: el contacto de Beristáin en Valencia con éste fue entre 1773 y 1776, siendo Mayáns quien le puso delante la bibliografía inacabada de Eguiara (datos de Millares Carlo, pág 344).

11 Joaquín García Icazbalceta, Bibliografia mexicana del siglo XVI, México, 1886 (ed. de Millares Carlo en México, FCE, 1954 y 1981).

12 José Toribio Medina, La imprenta en México (1539-1821), Santiago de Chile, Impreso en casa del autor, 1911; (hay edic. facsímil reciente en Amsterdam, N.Israel, 1965).

13 Desde José Gaos (En torno a la filosofia mexicana, México, 1952, pág. 83) a Juan Hernández Luna ("El iniciador de la historia de las ideas en México", Filosofia y Letras, 51-52 (México, julio-diciembre de 1953, págs. 65-80) se consideran los Anteloquia de Eguiara como el origen de la historia del pensamiento mexicano. Cf. Millares, Cuatro estudios..., pág. 240. 


\section{Insistencia sobre el origen polémico de la obra: respuesta a Martí.}

El amplio texto se construye en función de la polémica que la carta de Martí ha provocado, siendo frecuentes en él las referencias a éste, desde la justificación inicial del trabajo:

Muy lejos estábamos de pensar en este proyecto de una Bibliotheca mexicana, por hallarnos ocupados, ora en las tareas académicas o en las diarias elucubraciones teológicas propias de la cátedra, ora en la elaboración de obras relacionadas con estos asuntos, como son sermones sagrados y otros trabajos tocantes a nuestra profesión de teólogos, cuando llevados de la costumbre de emplear el tiempo y el descanso que tales tareas nos dejaban en la lectura de otros libros más amenos y escritos en una más elegante latinidad, vinieron a caer en nuestras manos los doce de Epistolas del deán de la iglesia de Alicante don Manuel Martí...(pág. 55, ed. Millares Carlo),

y, tras narrar el contenido de la epístola, afirma:

Mientras estos pensamientos bullian en nuestra mente y dábamos remate a la carta de Martí, ocurrísenos la idea de consagrar nuestro esfuerzo a la composición de una Bibliotheca mexicana, en que nos fuere dado vindicar de injuria tan tremenda $y$ atroz a nuestra patria y nuestro pueblo, y demostrar que la infamante nota con que se ha pretendido marcarnos es, para decirlo en términos comedidos y prudentes, hija tan sólo de la ignorancia más supina (pág. 58).

En último extremo, sus dudas sobre el esfuerzo que debía realizar al escribir su Bibliotheca, obtuvieron respuesta en el contacto con amigos sobresalientes que le animaron a la empresa, sobre todo por el carácter pedagógico que la misma iba a tener, para que nadie repitiera los errores del deán alicantino:

Bien sabemos que cualquier sujeto sabio y erudito de una nación culta mirará tal calumnia con desprecio y censura y que no sin estruendosa risa habrá de oírla o de leerla; pero siempre es de temer que aparezcan por ahí otros don Manuel Martí, que habiendo consagrado por entero su erudición y desvelos al cultivo de las lenguas griega y latina, a los encantos de la poesía y a la exhumación de las antiguas inscripciones romanas, poco se han cuidado de lo demás, y que, desconociendo en 
absoluto historias y cosas sabidísimas de muchos hombres doctos, vayan a sumarse a la opinión del deán de Alicante, y dejándose arrastrar por los prejuicios y engañosas apreciaciones de su carta, acaben por participar de idénticos errores y se lancen a divulgarlos (pág. 59).

A lo largo de la réplica insistente, con más de treinta citas emplazando ante sus errores al deán alicantino, Eguiara quiere desmontar globalmente a su enemigo, no sólo a través de las referencias a su ignorancia de los asuntos sobre los que ha opinado, o afirmando que propaga sus errores "ab plenis buccis", sino, sobre todo, demostrando un conocimiento singular de la biografia del personaje combatido, de quien nos da datos como los que comento a continuación.

\section{Un conocimiento singular de Martí.}

Eguiara quiere, al tiempo que lanza sus argumentos, reinterpretar detalles de la biografía del propio Martí que expliquen su razonamiento y demostrar un conocimiento sobresaliente sobre la misma. E indudablemente lo hace. Sabe, por ejemplo, que Martí mantiene una actitud similar a la que ha manifestado sobre México en relación a España, y asf confiesa que al leer su obra:

...nos dolíamos de ciertos ataques con que en más de una ocasión intenta su autor zaherir a los profesores y de sus frecuentes apreciaciones encaminadas al desprestigio de los españoles en lo que toca al cultivo de las disciplinas literarias...(pág.56),

pero conoce además otros datos que no sólo están en sus Eptstolas:

1) En su prólogo IV, dedicado a defender la cultura de "los antiguos mexicanos", donde, como en los dos anteriores, evidenciará su conocimiento del mundo cultural precolombino, planteamiento sobresaliente que trataré en un siguiente epígrafe, cita múltiples textos que evidencian ese mundo cultural, para centrarse en una reseña de las Actas de Leipzig donde se da cuenta de la obra Giro del mondo de G.F.Gemelli Careri, donde se hace el elogio de la antigua civilización. Pues bien, como colofón del argumento concluye Eguiara: "Hasta aquí 
el testimonio de los sabios de Leipzig, que acaso no será muy del agrado de Martf, por haberle aquéllos censurado, y no sin razón, en el tomo I, pág. 403 de los Nuevos Suplementos de las Actas, algunos extranjerismos de su estilo".

2) El prólogo VII, dedicado a resaltar una descripción de México realizada por Jean Bissel en la que describe la naturaleza de las colinas que rodean la ciudad como un anfiteatro, le sirve a Eguiara para coger por los pelos el término y contarnos que Manuel Martí se atribuyó el descubrimiento del teatro romano de Sagunto, cuestión sobre la que polemizó Juan Martínez Salafranca, en el Diario de los Literatos de Espafia (tomo 3, pág. 189). La alusión está referida a una famosa Disertación de Mart́́ en la que demostró que era teatro el considerado anfiteatro, cuestión, la de la paternidad de Martó del descubrimiento, que rebatió el citado Martf́nez Salafranca, aduciendo un texto de Mario Arecio en 1554 que citaba el teatro como tal, y en la que intervino Mayáns apoyando a Martí.

3) El prólogo IX está dedicado a incidir sobre todo aquello que, por su trabajo, Martí debió conocer y no conoce: su condición de bibliotecario del cardenal Sáenz de Aguirre en Roma, y antes de Luis de la Cerda en Madrid; sus visitas frecuentes a la Biblioteca Vaticana, mientras estuvo en Roma, le debieron enseñar que existían códices mexicanos, como descubrio Kircher. Tampoco su trabajo sobre la Bibliotheca Hispana Vetus de Nicolás Antonio, de la que fue editor en 1696 por encargo del cardenal Aguirre, no le hizo mirar probablemente la Bibliotheca Hispana Nova que aporta muchos datos de ingenios mexicanos. Tampoco al cuidar la edición de la Colección de Concilios de España y el Nuevo Mundo que preparó Sáenz de Aguirre y editó Martí reparó en el Concilio mexicano (de 1585) calificado por Aguirre de "sapientísimo".

Los argumentos, como he dicho, demuestran un conocimiento singular de aspectos de la vida de Martí. Y, por las citas, de materiales esenciales de la Preilustración europea (las Actas de Leipzig) y española (el Diario de los literatos). Aunque también, probablemente, el argumento del anfiteatro de Sagunto proceda parcialmente de la lectura 
de la biografía de Martí escrita por Mayáns, material que en última instancia (publicado en 1737) pudo servir a Eguiara para entender al personaje al que estaba combatiendo, aunque en ningún caso cite al erudito de Oliva ${ }^{14}$.

\section{Reivindicación de "los antiguos mexicanos": en la trayectoria de la defensa indígena.}

Nos llamará profundamente la atención la gran cantidad de datos que utiliza Eguiara para combatir una de las bromas de Martr, quien al hablarle a Antonio Carrillo de los indios decia: "Los mejores maestros, por Hércules". Eguiara hace acopio de nombres y de obras, desde los cronistas de indias a autores contemporáneos, para demostrar "la ilustración de nuestros indios, trayendo a la palestra sus códices y bibliotecas" (Prólogo II), su escritura (Prólogo III), sus monumentos (Prólogo IV), sus centros de enseñanza (Prólogo V), su afición por la poesía, la oratoria y la medicina (Prólogo VI).

Una parte consistente del texto se dedica a esa evocación de la antigüedad mexicana que puede sorprendernos $y$, desde luego, antedatarnos una polémica y sus resonancias históricas ${ }^{15}$. Eguiara demuestra

14 La biografía de Mayáns fue conocida en el círculo de Eguiara, como veremos luego a propósito de Arce y Miranda. En ella, ed. cit., pág. 179 ss. se da cuenta de todo lo referente al teatro de Sagunto. Sin embargo, la réplica de Martínez Salafranca es posterior, de 1736, y obtuvo respuesta de Mayáns en 1737, por lo que queda demostrada una lectura directa de Martínez Salafranca, quien replicó otra vez a Mayáns en el Diario de los literatos de España, en 1737 (los datos del vol. y págs. son los que cita Eguiara). Sobre Mayáns en América es interesante el dato que aporta Germán Cardozo Galué, Michoacán en el Siglo de las Luces, México, El Colegio de México, 1973, pág. 85, a partir de la reforma del plan de estudios en la Universidad de Quito en 1791 por el obispo Pérez Cálama en el que los estudios superiores de Gramática se harían mediante la Rethorica de Mayáns (Valencia, Jerónimo Conejos, 1757), ejemplo junto a otros textos de Cicerón y Nebrija.

${ }^{15}$ De una manera general, se sigue enunciando el "indigenismo" dieciochesco a partir de las obras de los jesuitas americanos expulsos como Clavijero, Pedro José Márquez o el Padre Veytia, según planteaba Luis Villoro en Los grandes momentos del indigenismo en México, México, El Colegio de México, 1950, quien centra en estos tres el "indigenismo" del XVIII. Y lo secunda Miguel León 
conocer dos antecedentes que no pueden sorprendernos, puesto que son testimonios del siglo anterior: Carlos de Sigüenza y Góngora en lo referente a las antigüedades mexicanas ${ }^{16}$, y el arzobispo Juan de Palafox y Mendoza en su Virtudes del indio ${ }^{17}$. Pero no hubo en ellos el tono polémico que Eguiara da a su obra de 1755, un tono que anticipa, como digo, lo que Antonello Gerbi lllamó La disputa del Nuevo Mundo y que habrá que situar como disputa europea (el jesuita Clavijero, por ejemplo, frente al abate De Pauw) bastante entrada la segunda mitad del siglo. La obra ofensiva de De Pauw es de 1768, y la respuesta de Clavijero (por citar una de las más emblemáticas) es de $1780^{18}$.

Portilla en Los antiguos mexicanos a través de sus crónicas y cantares, México, FCE, 1972, $2^{2}$ ed, pág. 10.

${ }^{16}$ Del matemático, poeta y narrador mexicano Carlos de Sigüenza y Góngora (1645-1700) demuestra conocer su obra erudita Libra astronómica y filosófica, México, Herederos de la Viuda de Bernardo Calderón, 1640; su Theatra de virtudes politicas que constituyen a un príncipe: advertidas en los Monarchas antiguos del Mexicano Imperio..., México, Imprenta del autor, 1606; y su Cyclographia.

${ }^{17}$ Del obispo Palafox y Mendoza (1600-1659) cita Eguiara su actividad como organizador cultural: la fundación del Colegio de San Juan y San Pablo; la importancia de su biblioteca, donada al Seminario de México en 1646; y, por los argumentos centrales de su defensa, su tratado Virtudes del indio, vol. 6 de las Obras, Madrid, Pablo de Val, M. Alegre, María de Quiñones y Bernardo de Villadiego, 1659-1671.

${ }^{18}$ En 1768, en Berlín, apareció la obra de Corneille de Pauw, Recherches philosophiques sur les Américains, Ou Mémoires intéressants pour servir à l'histoire de l'espèce humaine (Berlín, G.J.Decker, imprimeur du Roi, 1768, 2 vol.) que se convierte en un alegato central ilustrado contra América: la degeneración de los americanos, el carácter pernicioso del clima y la naturaleza, la fundamentación de la servidumbre de los indios, etc. Son ideas que abren un debate central sobre América, secundando de Pauw ideas del siglo XVI de la teoría de los climas de Bodin (Methodus ad facilem historiarum cognitionem, 1566), y secundado a su vez De Pauw por Georges-Louis Leclere de Buffon y por Guillaum-Thomas-François Raynal. Contra las ideas de De Pauw, entre tantas respuestas polémicas, es esencial la del jesuita mexicano expulso Francisco Javier Clavijero, Storia antica del Messico, Cesena, Gregorio Biasini all'insegna di Pallade, 1780. Para una amplia reflexión sobre este debate es esencial el libro citado de Antonello Gerbi, La disputa... El americanismo de los jesuitas expulsos es tratado ampliamente por Miquel Batllori en La cultura hispano-italiana de los 
En 1755 publica Eguiara una abultada defensa del mundo precolombino, que va de los testimonios significativos de Fray Bernardino de Sahagún, de quien demuestra conocer datos de su obra, inédita en la mayor parte, a los escritos del padre Atanasio Kircher. Reivindicado el conocimiento, otro argumento es la bondad y la autenticidad religiosa indígena, para lo que cita varias veces a Palafox y Mendoza. Un silencio significativo es, sin embargo, el del padre Las Casas ${ }^{\mathfrak{i g}}$, mientras demuestra conocer a Antonio de Solís, a Francisco de Gomara, a Fray Juan de Torquemada o al padre Acosta.

Al intentar demostrar la consistencia cultural indígena, incluye Eguiara una crítica a las destrucciones operadas por los conquistadores $\mathrm{y}$, al tratar de los códices indígenas -comenta que ha conocido a Boturini $^{20}$ en México-, dice que los religiosos no entendieron las

jesuitas expulsos, Madrid, Gredos, 1966.

${ }^{19}$ Que las ideas de Las Casas estaban presentes desde dos siglos antes en el ámbito mexicano y en el debate ilustrado europeo no ofrece lugar a dudas y en la obra de Gerbi citada hay suficientes testimonios, siendo especialmente importante el ataque de De Pauw contra el dominico español. Silvio Zavala, en Filosofia de la conquista (México, FCE, 1947), cap. "Igualdad dieciochesca" ha aportado también múltiples datos documentales. Por eso resulta extraño que una figura como Eguiara no lo mencione. Habría que indagar en esa línea el papel que ocupaba Las Casas en el pensamiento mexicano del XVIII. En el pensamiento de los jesuitas no parece figura muy habitual, recogiendo sólo Batllori (op. cit., pág. 582) una Refutación de Las Casas del mallorquín Rafael Diosdado Caballero. En la obra de Zavala encontramos datos sobre el jesuita Domingo Muriel, de la Universidad de Córdoba de Tucumán, quien tercia contra las acusaciones de De Pauw a fines de siglo. La cuestión queda como línea pendiente, aunque la polémica sobre Las Casas se nos sale del marco del texto de Eguiara, para entrar en otros debates habituales como la brutalidad de la Conquista. En cualquier caso, en la lectura de Eguiara, lo que nos interesa es por qué ninguna vez le sirve para apoyar sus argumentos, y a esto sólo podremos llegar con una indagación más amplia sobre Las Casas en la Nueva España del siglo XVIIl y en el contexto cultural preciso de Eguiara.

${ }^{20}$ Dice Eguiara textualmente, al hablar en el Prólogo II de los códices aztecas conservados: "En nuestros días se conservan gran número de esos volúmenes recogidos de diversas partes por la incansable actividad y no menor entusiasmo del ilustrado caballero Lorenzo Boturini, que cuando vivía en México nos los enseñó muchas veces y dió particular noticia de ellos en el Catálogo de su Museo Indiano" (op. cit, pág. 67). Esta obra aparece como apéndice al trabajo principal de Boturini Idea de una Nueva Historia General de la América Septentriona, 
pinturas y los signos que contenían y

...esto fue causa de que los varones apostólicos, predicadores de la fe católica y primeros fundadores de la iglesia mexicana, desconociendo el significado de lo que debajo de tales velos se ocultaba, vinieran a considerarlos como frutos de las hechicerías indígenas y trasunto de sus cultos idolátricos e imágenes demoníacas, por lo que, buscándolos afanosamente por doquiera, los entregaron al fuego, acarreando lamentable pérdida a la historia y antigüedades americanas (pág.65-66).

Afortunadamente, nos comenta a continuación, algunos indios conservaron obras en secreto y las sacaron luego a la luz, lo que ha permitido reparar el desconocimiento.

La actitud de Eguiara, indudablemente, nos lo debe situar como figura clave de la reivindicación cultural indígena en México, y como perspectiva nos debe hacer revisar, en lo concerniente al siglo XVIII, la propuesta que Luis Villoro realizó centrada en Clavijero, Márquez o Veytia ${ }^{21}$.

\section{EI mundo colonial: similitud con el Europeo}

Junto a los datos que intentan demostrar la cultura de los aztecas, hay una parte sustancial de opinión que se intensifica cuando quiere probar que no hay ninguna inferioridad de los americanos en relación a los europeos, cuestión que centra necesariamente en el mundo colonial, para lo que utiliza argumentalmente al padre Feijoo, cuya difusión en América era extensa ${ }^{22}$, sobre todo en dos trabajos muy

Madrid, 1741. El viaje de Boturini a México fue en 1736. Por supuesto que Martí, muerto en el 37, no podía conocer ninguno de estos datos ni saber quién era Boturini.

21 Cf. nota 15.

${ }^{22}$ Los dos textos centrales de Feijoo, para el debate de América, son "Mapa intelectual y cotejo de naciones" y "Españoles americanos", en Theatro crítico universal, Madrid, En la Imprenta de la viuda de Francisco del Hierro, 1726, en vol. II y IV respectivamente. Sobre la recepción de Feijoo en América, su difusión también en el virreinato del Perú, la atención que la Inquisición tiene hacia su obra a partir de 1759 , hay suficientes datos en el libro de Gerbi, La 
conocidos como su Mapa intelectual y cotejo de naciones y Españoles americanos, centrándose Eguiara en dos argumentos que Marț no ha utilizado: el prematuro ingenio y la temprana decrepitud de los cerebros en América, y el que señala levemente sobre la influencia del clima y la naturaleza en la degeneración de los individuos. Son dos argumentos centrales del debate que se realiza en el interior de la Ilustración, teniendo antiguos precedentes como la renacentista teoría de los climas de Bodin, y que alcanzarán la plenitud del debate en De Pauw, Buffon y Raynal. Eguiara conoce algunos precedentes de estas posiciones, a los que cita, como François Correal y Juan de la Puente ${ }^{23}$.

Importantes son los datos sobre las Universidades, las Bibliotecas en Nueva España o el catálogo de cerebros, algunos ancianísimos, para desmontar estas teorías, y globalmente, a través de los datos de instituciones, las afirmaciones de Martí. Dedica el prólogo VIII a ofrecer al joven Antonio Carrillo datos y nombres, y le dice:

Ya ves a cuántos y cuán diversos maestros podrás dirigirte a tu llegada a la ciudad de México. En otros lugares de este reino, como Puebla, Michoacán, Oaxaca, Durango, Guatemala, Yucatán y otros anteriormente citados, te ocurrirá lo propio: hallarás en gran número personas que te instruyan en el conocimiento de las letras y en toda clase de erudición (pág. 103).

En la perspectiva polémica, tras enumerar los nombres y lugares, Eguiara quiere señalar a través de otros argumentos y personas cuál es el pecado último de Martí, su visión del mundo limitada a Europa, por lo que su trabajo

polémica..., pág. 234 ss. Al círculo de Eguiara llegaría la obra de Feijoo a través de Arce y Miranda.

${ }^{23}$ En el Prólogo XX, pág. 219 ss., aparece la cita y la réplica a Correal, por su Voyages aux Indes Occidentales, París, 1732, y a fray Juan de la Puente, cuya obra que, como la de Correal, está escrita en el siglo XVIJ. Sobre fray Juan de la Puente habla Nicolás Antonio en su Bibliotheca hispana nova, por lo que hay que presuponer que Martí conocería a éste, también precursor probable de su carta. 
mostrará cómo florecen en América las bellas letras a bastantes europeos que, como don Manuel Martí, parecen creer que la erudición

y las ciencias no pueden existir más que en sus escuelas (pág. 208).

No siendo éste el espacio para seguir comentando ampliamente la obra de Eguiara, pasaré a situar otros testimonios que indican la gran recepción polémica que tuvo la carta de Martí y, posteriormente, desarrollaré algunos apuntes de revisión a través de los datos aportados.

\section{Otras réplicas}

Cronologicamente, la primera réplica que podemos aportar es la de Juan Gregorio de Campos y Martínez, titulada Oratio apologetica ${ }^{24}$. Se pronunció en Noviembre de 1745 en la apertura del curso universitario. Conocemos el texto por la descripción que de él hace Mariano Beristain, el sucesor de Eguiara con su Bibliotheca Americana, donde dice: "Esta oración fue pronunciada en la apertura de los estudios de la Universidad de México, del año 1745, en que estaban recién llegadas a la Nueva España las cartas latinas del deán de Alicante, Manuel Martí, y la miserable e injuriosa idea que manifiesta en la Epístola 16 del libro 7 del tomo 2, sobre la literatura mexicana, estimuló a nuestro doctor a hacer en esta oración la apología de su patria. La Universidad acordó imprimirla, y la dirigió al Sr. Felipe V, por mano del Ilmo. Sr. D. Francisco Goyeneche, marqués de Belsunce, decano del Consejo y Cámara de las Indias". El mismo Beristáin nos presenta al autor: "Campos (P.D.Juan Gregorio).- Natural de la villa de Orizaba en el Obispado de Puebla de los Ángeles. Estudió en México la filosofía, las matemáticas y la medicina, y sobresaliente en todo, recibió los grados de maestro $\mathrm{y}$ doctor, $\mathrm{y}$ fue Catedrático de Prima de medicina, $\mathrm{y}$

${ }^{24}$ Oratio apologetica, quae velut supplex libellus potentissimo Hispaniarum Regi Philippo V.Por manus III.D. D. Marchionis de Belzunce, \& c. porrigitur a Regia Pontificia Mexicana Academia Ubi 15. Kaleend. Novemb. 1745 pro solemni generalium studiorum auspicio habita fuit a D.Joanne Gregorio de Campos, \& Martinez, Medicae facultatis Doctore, olim huius Academiae Consiliario, Mexici, ex Regali Summae Administrationis, Sacrorurumque Librorum Typographia, apud D. Mariam de Rivera, in publica via de Empedradillo. Anno MDCCXLVI. (Toribio Medina, VII, 3756). 
protomédico del tribunal del protomedicato de la Nueva España. Habiendo enviudado, abrazó el estado eclesiástico y se retiró al oratorio de San Felipe Neri, donde no fue menos útil a la salud espiritual, que lo habra sido a la corporal de los mexicanos"25.

El jesuita Vicente López escribió su Aprilis dialogus ${ }^{26}$ como Prólogo a la Bibliotheca de Eguiara. Se trata de un diálogo entre un español, un belga y un italiano acerca de las ideas sustentadas por el deán Martf, y un elogio a la obra de Eguiara. Un fragmento es una alabanza irónica del papel desempeñado en México por Manuel Martí, afirmando al tratar la respuesta de Eguiara:

Italiano: $[\ldots]$ ¿. y el deán proporcionó las causas para escribirla?

Belga: Ciertamente, las proporcionó.

Italiano: $\mathrm{Si}$ así está el asunto me aplicaré al instante; de inmediato cantaré una palinodia y daré muchísimas gracias a Martí.

Belga: Puedes y debes, y escucha y tenme fe a mí que lo narro. Estando sentados en familiar coloquio el doctor Eguiara y yo, y habiendo recaído la conversación sobre las letras, él me leyó, y por cierto sílaba por sílaba, tal epístola del deán; habiéndola oído, efectivamente, en verdad, primero enrojecí, luego súbitamente palidecía por tan inaudito juicio sobre los americanos, finalmente me horroricé. Pero luego que me recuperé: "¿Por qué -dije- tú, Eguiara, no vindicas estas cosas y de tanta abundancia de mies de los mexicanos, cuyos ingenios, por cierto, fueron muy sobresalientes, y escoges algunos a partir de los cuales el alicantino reconozca que los estudios de las optimas letras entre vosotros están en efervescencia y que los mexicanos tienen su Atenas. Más aún -añadió él con voz sumisa- ojalá pueda, auspiciándolo Dios, erigir una Bibliotheca para Martí y de volumen y magnitud no menor que la que fue escrita por Nicolás Antonio... (pag. 10)

${ }^{25}$ Beristáin, op. cit, t. I, pág. 129.

${ }^{26}$ Llegamos al texto a través de Beristáin, quien decía que se trataba de "una invectiva contra el famoso deán de Alicante, Manuel Martí, y una apología de la literatura mexicana". Al acabar de redactar estas notas conseguimos la edición Vicente López, Diálogo de Abril, Introducción, traducción y notas de Silvia Vargas Alquicira, México, UNAM, 1987. La importancia del texto exige un comentario más amplio que el que aquí podemos hacer. 
Sin entrar directamente en la polémica con Marti, a quien no cita, pero citando profusamente los argumentos de Eguiara, e incidiendo concretamente sobre la influencia benéfica de la naturaleza americana en los cerebros, hay también un prólogo del padre Vicente López, al reeditar casi un siglo después de su escritura las Constituciones de la Real y Pontificia Universidad de México del obispo y virrey de México Juan de Palafox y Mendoza 27 .

También desde México, en 1760, tercia en la réplica Andrés de Arce y Miranda, dedicando el tomo III de sus Sermones a Eguiara, en un largo texto fechado el 20 de Septiembre ${ }^{28}$. La dedicatoria llama la atención por los datos que aporta sobre el conocimiento de Manuel Martí en México, al margen de los tintes polémicos de la famosa carta. Así, al describir las virtudes moderadas de Eguiara, su rigor en las costumbres y la sencillez de la casa de quien era rico por su patrimonio familiar, habla sin embargo de la importante biblioteca que tenía: "sólo se veía una copiosa y esquisita librería, de que se utilizaban todos los que concurrían, guardándose en ella exactamente (aún antes de haberse promulgado) todas aquellas preciosas leyes que estableció para el uso y buen gobierno de su Biblioteca el famoso deán de Alicante, y que agradaron tanto al célebre cardenal Cienfuegos, que no dudo afirmar el que si viviese Gravina, las colocara entre las que ilustró de las doce Tablas", haciendo referencia por parte de las normas bibliotecarias a la Epístola 24, del Libro XII, del Epistolarium de Martf; y tomando la anécdota del cardenal Cienfuegos de la vida de Martí de Mayáns.

Otro dato importante que aporta Arce y Miranda consiste en la existencia de una "Academia Eguiarense", localizada en el Oratorio de Nuestro padre San Felipe Neri, informando que los alumnos de la academia elaboraron un libro de Selectos elogios a Eguiara, dirigidos en esta actividad por el teólogo y jurista D. Manuel García Arellano. El

${ }^{27}$ El texto es de hacia 1640 , la edición que comento es la segunda aparecida en 1775, en la Imprenta de Don Felipe de Zúñiga y Ontiveros (Toribio Medina, VI, n. 5836).

${ }^{28}$ El vol. III es Sermones varios del Doctor D. Andrés de Arce y Miranda, México, En la Imprenta de la Bibliotheca Mexicana, 1761. El texto en Toribio Medina, op. cit., vol. VIII, págs. 411-418. 
libro en cuestión, que no hemos podido conseguir en el momento de redacción de este trabajo, está descrito por Toribio Medina ${ }^{29}$.

Tras describir la importancia de la Bibliotheca mexicana de la que ya ha aparecido el primer volumen, aborda Arce y Miranda la defensa de la Universidad de México y el papel que Eguiara está teniendo en ello, sobre todo en la restitución de su honor, que ha sido como devolver la vida a la Universidad:

pues el vivir sin honra no es vida. Sin ella vivía nuestra Academia, y toda la Nación Americana, por varias preocupaciones y atroces calumnias, que algunos, o desafectos o ignorantes de las cosas de América, derramaron en la culta Europa. Entre ellos, el que cortó más delgada la pluma para hacer más penetrante la herida, fue don Manuel Martí, deán de Alicante, sujeto verdaderamente eruditísimo en lo que toca al mundo viejo; pero ignorantísimo por lo que mira al Nuevo: al que pinta con los colores de la más tersa latinidad como a una selva inculta, llena sólo de malezas de toda especie de vicios, y con un estilo verdaderamente ciceroniano describe el distrito de nuestro México como un pais de ignorancia, poblado no de hombres, sino de brutos, que no saben ni desean saber, donde no hay discípulos que quieran aprender, cuanto menos maestros que puedan enseñar; donde no se ven más bibliotecas, ni libros, que los que llaman los negociantes libros de caja. A tan monstruosas imposturas, y a tan visibles falsedades pronunciadas por un sujeto tan celebrado en Europa, y que hace del Estoico en sus cartas, se dio por sobrada razón agraviada toda nuestra Nación Mexicana, y con mucha especialidad aquella nobilísima porción que compone el respetable Cuerpo de su muy ilustre e insigne Universidad. Entre tantos varones doctos como abriga en su gremio, americanos y europeos, V.S. fue el que, sin embargo de su trabajada salud $\mathrm{y}$ de las ocupaciones heterogéneas de sus graves y varias incumbencias, celosos de la gloria de la patria y del honor de la Academia, se ofreció a la defensa de tan poderoso enemigo; $y$ a este fin trabajó y dio a luz la Bibliothe ca Mexicana, con que ha conseguido una completa victoria, derribando a aquel gigante y cortándole la cabezacon las mismas armas; pues con la misma pureza de dicción y elegancia de

${ }^{29}$ Elogia selecta é variis, quae Mexicearum scholarum more ab alumnis Academiae S. Philippi Neri elaborata sunt.., México, Ex Nova Typographia editioni Bibliothecae Mexicanae destinata, 1755. 
estilo que usó el de Alicante, se explica en toda ella V.S. No es dudable que el error de Martí fue el mayor que se pudo incurrir en lo histórico; y si no le excusase la ignorancia, fuera su culpa de las más graves que se pueden cometer en lo moral.

En los párrafos siguientes, aborda sin embargo otro tipo de argumentación, basándose en que "si el de Alicante querfa desacreditar la Nueva España [...] en aquella parte en que ella se conoce defectuosa", ellos lo habrían aceptado, planteando los defectos de la excesiva división en escuelas y grupos, o de la envidia que lleva a que cerebros como Sor Juana hayan sido conocidos en México porque han sido reconocidos en Europa. Pero sobresalen los errores de Martí, abordando que con su obra la acción de Eguiara "no ha estado sólo en vencer al de Alicante: también ha deshecho otros adversarios, aunque no de tanta penetración ni tan superiores luces". El argumento final critica la idea de que la inteligencia decrece tempranamente en América, y recoge los argumentos de Feijoo para afirmar lo contrario.

Más importante es el libro Llave del Nuevo Mundo de José Martín Félix de Arrate, quien desde Cuba recoge en 1761 la polémica y demuestra conocer la Bibliotheca de Eguiara. En el capitulo "Letrados ilustres de la Habana" da datos del Licenciado D. Francisco de Castilla Borroto, de quien afirma que es "sujeto muy acreditado por su literatura e integridad", a través de Eguiara. En el capítulo XXVII, al hablar de la Real y Pontificia Universidad de San Jerónimo de La Habana, dedica los logros de la Universidad para contradecir a Martí en un largo párrafo que por su interés reproduzco:

El número de las Cátedras que al presente se leen en esta Universidad son [...]. Aunque no tienen hasta ahora dotación ni congrua ninguna, se leen y asisten con esmero y aplicación, siendo muy frecuentes las conferencias, actos y quodlibetos en que manifiestan los catedráticos su literatura y los discípulos su aprovechamiento, admirándose en los despuntes de unos y de otros aquellas sublimes y anticipadas luces de entendimiento que celebró la elegancia del Conde de la Granja en los ingenios peruanos y de que gozan en este país, adelantándose en ellos la razón a la edad, pues aún en lo más florido de los años son muy provechosos en las ciencias: ejemplo que bastaría, cuando faltasen otros en las Indias, para desmentir el concepto o desvanecer el error del deán de Alicante que, dormitando como Homero, estampó en 
una de sus epístolas latinas. Pues no sólo nos hizo el poco favor de persuadirse que en estas partes no había maestros para enseñar, pero añadió la injuria de decir que no había tampoco quien desease saber: hipérbole con que quiso encantarnos con los brutos, y degenerarnos de hombres, cuando según axioma filosófico: Omnis homo naturaliter scire appetit. Lastimosa ceguedad de un varón tan autorizado como instruido, el no haber encontrado, en tantos escritos como corren, noticia de las muchas escuelas que hay en estas regiones y sujetos insignes con que han ilustrado la república de las letras, para no haber ofendido la verdad, agraviando su estimación y el crédito de los indianos.

Pero por más que se pretenda deslucir la habilidad de éstos o hacer creer la ninguna aplicación a las letras que hay en estas partes, bastan a acreditar lo contrario las famosas universidades, insignes colegios y célebres ingenios que gozan estas regiones e ilustran estos países, sobrándonos los testimoníos que podríamos alegar, cuando sólo en el nuestro, que es de los más ceñidos, hay personas que enseñen e individuos que aprendan, como se verifica en la copia de oyentes y multitud de cursantes que ocurren de toda Isla a las aulas de esta Universidad, sin otro objeto que el de saber por sólo saber.

No es tan único en este sentir el citado Martí, que le falten aún muchos secuaces y partidarios, y aunque pudiera servirle de consuelo a los ingenios de estas provincias el que padezcan no muy desigual concepto los españoles en la aprensión de otras naciones europeas, que decantan su poco adelantamiento en las artes y las ciencias, atribuyéndose cada una a sí la entera posesión de las bellas artes y las conocidas ventajas en la cultura de todas sus facultades, no son ni los juzgo tan vulgares o tan necios que les temple el dolor de su propia injuria el ver lo que experimentan sin justicia aquellos que la motivan, y más tocándoles tan de lleno la común ofensa de la nación castellana de quien no le distingue otra cosa que el clima, siendo el nuestro tan benigno y admirable para la producción de útiles y nobles ingenios, capaces de aplicarse a los estudios y de cultivar las ciencias... ${ }^{30}$.

Junto a la diatriba habitual a Martí, algunas referencias finales nos encaminan de nuevo a las relaciones naturaleza-cultura mediadas por el individuo: la polémica cientffica del siglo XVIII aparece de nuevo como transfondo. Por otra parte, la amplia elaboración histórica, geográfica,

30 José Martín Félix de Arrate, Llave del Nuevo Mundo, Prólogo y notas de Julio J. Le Riverend Brusone, México, FCE, 1949, págs. 141-142. 
política y cultural que José Martín Félix de Arrate realiza, tiene a partir de este párrafo un carácter de respuesta global a las consideradas injurias de Martf.

\section{Apostillas a una polémica}

Las notas que siguen quieren indicar básicamente algunas líneas de desarrollo que permiten las réplicas que la carta de Mart́ produjera. $\mathrm{He}$ reducido al máximo la información, intentando hacer hincapié en los materiales referenciales que deberán ser tenidos en cuenta para una reflexión global sobre el asunto tratado hasta aqur, con el convencimiento de que quizá, al seguir las notas propuestas, podremos llegar a una revisión del sentido global de la polémica.

\section{El origen de las ideas de Martí sobre América}

El erudito mexicano Federico Gómez de Orozco, al prologar el trabajo de edición de los Prólogos de Eguiara realizado por Millares Carlo, da una clave importante para situar el origen de las ideas de Martí. Es frecuente, en la réplica de los mexicanos, señalar que Martí, editor de la Bibliotheca Hispana Vetus de Nicolás Antonio, por mandato del cardenal Aguirre, bien podría haber ojeado la Bibliotheca Hispana Nova, donde se encuentran recogidos los nombres de ingenios mexicanos. Sin embargo, sugiere Gómez Orozco que el origen de la idea central de Martí, bien podría estar en el propio Nicolás Antonio: Martí, al ordenar los papeles de éste en sus trabajos de edición de la Bibliotheca Hispana Vetus, encontraría las cartas a Juan Lucas Cortés, publicadas luego por Mayáns en la edición de Censura de historias fabulo$\operatorname{sas}^{31}$, y habría leído aquellos párrafos sobre América en los que Nicolás Antonio decía a Lucas Cortés:

${ }^{31}$ Nicolás Antonio, Censura de historias fabulosas, Obra pósthuma de D. Nicolás Antonio... Van añadidas algunas cartas del mismo autor $i$ de otros eruditos. Publica estas obras Gregorio Mayáns y Siscar, Autor de la Vida de Nicolás Antonio, Valencia, Antonio Bordázar de Artazu, 1742. 
Con alborozo he leído la jornada que V.M. determinaba hacer a Madrid, que ya supe por otras cartas haberla ejecutado en compañía del señor conde de Villaumbrosa, de cuyo juicio tan experimentado ha hecho una nueva experiencia en la que ha hecho de V.M. y de sus buenas partes para hacerlas lucir y darle campo para que muestre su habilidad y espiritu; y no dudo que ha de resultar deste favor y apoyo que V.M. se vea en alguno de los puestos que merece "dentro de Castilla y no en Indias", porque, como V.M. entiende bien, ellas no son sino para hombres que quieren ir a sepultarse en un olvido de todo lo virtuoso y precioso de Europa, teniendo por precioso solamente y por virtuoso el oro que da aquella tierra; y ser éste su sentimiento de V.M. no lo debo extrañar, pues conozco que vive con lo que a aquellos míseros desterrados del otro mundo "les falta, que es la comunicación de los literatos y manejo de las obras de entendimiento", de que tan fecundo es hoy el suelo desta parte del mundo, en donde Dios le dio naturaleza, no para que vaya a "tratar con indios", sino sólo para averiguar de las Indias, cuando haya de aplicarse a cosa de ellas, de donde pasaron allí sus habitadores a reírse de Pereiro con sus preadamitas, origen de los habitadores americanos, según su génesis antimosaica.

Pero, seguramente, a pesar del interesante señalamiento en Nicolás Antonio, el origen de las ideas de Martí hay que buscarlo en el ambiente cultural en el que está inmerso, en el mismo debate sobre las Indias cuyo origen está en su descubrimiento, en la otra cara de la idealización ilustrada del "buen salvaje", y, junto a todo esto, en la visión cultural sobre las colonias de alguien que no tiene, precisamente, una visión muy lejana de la metrópoli. Señalar Roma como objetivo al joven Antonio Carrillo está dentro de la visión negativa de España que Martí sustenta y, sobre ella, hay múltiples testimonios. Las ideas del siglo, y su misma visión sobre España -ya lo detectó Eguiara en un párrafo que cité antes- sustentan la perspectiva de lo que en México iban a considerar como una afrenta.

\section{Sobre la recepción y la universalidad de Martí}

Que la fama europea de Martí fue extensa no parece a estas alturas un argumento sobre el que insistir. Sobre la fama americana de Martí, en los testimonios que hasta el momento hemos podido señalar, parece 
oportuno tener en cuenta que, al margen de la polémica, dos autores demuestran un conocimiento riguroso de su producción intelectual: Eguiara, por supuesto, quien aporta en su crítica varios datos de su biografia, y Andrés de Arce y Miranda, quien cita elogiosamente sus normas bibliotecarias, por cierto que a través de la Emmanuelis Martini vita de Mayáns ${ }^{32}$.

Los otros testimonios arremeten una y otra vez sobre el argumento central de la polémica, o saludan la victoria de Eguiara sobre el deán de Alicante. El primer testimonio, el de Juan Gregorio de Campos y Martínez, al haber sido pronunciado en la apertura de curso de la Universidad de México en 1745, indica la envergadura cultural que la polémica ya habría tomado, y señala la posibilidad de indagación documental en esa línea, siendo los archivos mexicanos un camino venturoso a transitar.

Al margen de la posibilidad de nuevos testimonios, lo que parece indudable es la dimensión del proceso cultural que la carta de Martí produjo y es en esa línea -reconocimiento por otra parte, aunque negativo, de un personaje que había muerto algunos años antes de que se desatara la polémica- donde los resultados pueden ser más fructíferos.

\section{Un último apunte sobre Martí: Antonio Carrillo.}

Sobre la carta de Martí, desconozco que se haya planteado alguna vez quién era el destinatario. Y, sin embargo, sería interesante hacerlo, porque en cualquier caso ocupa un lugar central en la vida del propio Martí: sabemos que debió hacer caso a los consejos del deán alicantino, porque Antonio Carrillo es Antonio Carrillo de Mendoza y era deán de

${ }^{32}$ El párrafo que cité antes de Arce y Miranda: "todas aquellas preciosas leyes que estableció para el uso y buen gobierno de su Biblioteca el famoso deán de Alicante, y que agradaron tanto al célebre cardenal Cienfuegos, que no dudó afirmar el que si viviese Gravina, las colocara entre las que ilustró de las doce Tablas" es traducción de "Adeoque eorum conservationis nitorisque amore scripsit Leges ad Bibliothecas pertinentes, quas plurimi viri eruditi suis praefixere. Cunque eas legisset cardinalis Alvarus Centigneus [...] non dubitavit scribere Gravinam si viveret, illas inserturum esse inter leges XII Tabularum" (ed. cit., pag. 244). 
Sigüenza durante los últimos años de Martí, quien se sorprende de que Mayáns poseyera en 1735 varias cartas que había enviado a Carrillo y que acababa de publicar ${ }^{33}$; el 17 de Agosto del mismo año le pide a Mayáns que le haga llegar al deán de Sigüenza un ejemplar del Epistolarium, cuestión que repite en carta del 24 de Agosto, mientras el 2 de Noviembre le pregunta si, tras el envío, éste "ha respirado"; el 7 de diciembre acusa recibo de una carta en la que Mayáns le comunica que ha pasado en Alcalá "buenos ratos" con el deán de Sigüenza y se queja de que no le hayan escrito, queja que reitera el 4 de enero de 1936, donde dice: "la carta del deán de Sigüenza, creo que es fantástica; pues ni en el correo passado ni en éste la he recibido". Por último, el 3 de Mayo de 1737, al comunicar Mayáns a Almeida la muerte de Marti evoca y reproduce unas décimas dedicadas a Antonio Carrillo por Martf, cuando se conocieron, dice Mayáns que en Roma, cuyo motivo es "la brevedad de nuestra vida y sus desengaños".

Antonio Carrillo siguió la vida intelectual que Martf́ le trazara, aunque con una dedicación menos asidua, puesto que sólo conocemos que escribiera un manuscrito dedicado a la historia de la Iglesia en Sigüenza ${ }^{34}$, y un curioso folleto de policfa municipal dedicado a impedir en Madrid los robos y la entrada en la ciudad de gentes perniciosas ${ }^{35}$.

${ }^{33}$ Aparecen éstas en Cartas Morales, Militares, Civiles i Literarias de varios Autores Españoles, Madrid, Juan de Zúñiga, 1734.

34 Noticia histórica de la institución, ritos y gobierno de la lglesia en Sigüenza, desde los tiempos en que se conquistó de los árabes, con una serie cronológica de sus obispos, desde los tiempos del tercer Concilio toledano hasta el año de 1751, 47 folios (Madrid, Biblioteca Nacional, Mss.Dd [52-58]).

${ }^{35}$ Clave methódica para impedir en Madrid y poblaciones del Reyno los robos y acogida de gentes perniciosas..., Madrid, Gabriel Ramírez, 1755. No puede ser suyo, sin embargo, un Papel dirigido al gobierno sobre el establecimiento de la tasa de los granos, fechado en 1790, del que da cuenta Aguilar Piñal en su bibliografía, a través de una cita de la Biblioteca de los economistas españoles de Colmeiro, aunque dice no haberlo localizado. Desde luego en 1790 nuestro deán de Sigüenza debía contar, por la fecha en la que le escribió Martí (1718, cuando Carrillo tenía 25 años), unos 97 años por lo que no estaría para preocuparse del grano, o sencillamente no estaría. 


\section{La academia eguiarense}

Señale antes la referencia de Arce y Miranda a la "academia eguiarense". Textualmente, decía éste, al referirse que no dejo entrar a persona del genéro femenino en su biblioteca particular: "Antes por asegurarla de ese riesgo, juzgó que pasaría V.S. sus asambleas al Oratorio de N.P.S. Felipe Neri, donde manteniendo el título de Academia Eguiarense, se ha dado ya a conocer por el libro de Selectos elogios que con tan bellas notas e ilustraciones dio a luz el ingenioso teo-jurista don Manuel García Arellano...".

Otro dato lo da Beristáin, al comentar precisamente el ejemplar de Elogia Selecta dedicado a Eguiara:

S. Felipe (Academia de).- Se estableció en México a principios del siglo XVIII, en la casa de los PP. del Oratorio de San Felipe Neri, por el P. Antonio Piñateli, mexicano, presbitero de la misma Congregación; y a los quince años se trasladó a la Universidad. Su primer instituto fue para el estudio de la filosofía y después se extendió al de la teología, derecho canónico y bellas letras ${ }^{36}$.

En el único trabajo de conjunto existente sobre las academias literarias en México ${ }^{37}$ no se da cuenta de estas referencias y no se incluye a la llamada "academia eguiarense" entre las estudiadas. Por una parte, sería lógico en cuanto que no es una sociedad literaria la de Eguiara, pero algunos datos podrían llevarnos a que también pudo ser una sociedad literaria.

Su base, como ya dijo Millares Carlo en su biografía, fue esencialmente teológica:

Desde el año 1709 mantenía una Academia que comenzó a actuar en el Oratorio de San Felipe Neri, de que fue devotísimo, y se trasladó luego a la Real Universidad, frecuentada por siete doctores teólogos, bachilleres, pasantes y cursantes, en la cual, dos días a la semana, se

${ }^{36}$ Cit. en Toribio Medina, op. cit, vol. VI, pág. 236.

${ }^{37}$ José Sánchez, Academias y sociedades literarias de México, University of Illinois, 1951; cap. "El siglo XVIII", págs. 34 ss. 
defendían conclusiones de teología escolástica y se resolvían casos de teología moral, bajo la presidencia de Eguiara, a partir de $1712^{38}$.

Y las múltiples intervenciones del Presidente en la Academia son esencialmente religiosas y teológicas ${ }^{39}$, pero ya Beristáin decía que la actividad, para él inicialmente filośfica de la Academia, acabó extendiéndose a las bellas letras. En una relación autobiográfica de méritos del propio Eguiara, fechada el 8 de Julio de 1757, nos dice éste textualmente:

Que asistió 24 años a la Academia de teólogos de la expresada Universidad llamada de San Phelipe Neri, y los 24 presidió todas sus conferencias escolásticas y morales y demás excercicios literarios, en la cual leyó 20 lecciones de media hora cada una, hizo 17 oraciones panegíricas, un certamen poético y un bejamen... ${ }^{40}$.

Las fronteras entre la sociedad literaria y la academia teológica tienden a ser así menos rígidas, y a incitarnos a indagar la realidad de la "academia eguiarense" de la que habló Arce y Miranda. Por otra parte, el propio Eguiara demostró tener una visión clara de las Academias literarias en su relación con el conjunto del saber cuando, al comentar la figura de Nezahualcoiolt (Prólogo V), decía:

Era tanta la sabiduria de dicho monarca que por obra suya se formó, a manera de Academia y bajo la presidencia de su hijo Xochiquetzalzin, un núcleo de poetas y músicos, que entre los texcocanos son muy numerosos, así como de astrólogos, historiadores y cultivadores de

${ }^{38}$ Millares Carlo, ed.cit, pág. 29.

${ }^{39} C f$. la bibliografía de Eguiara en los trabajos citados de Millares Carlo, donde aparecen múltiples intervenciones en la Academia.

${ }^{40}$ Eguiara, Prólogos.., pág. 49. En las relaciones autobiográficas que publica Millares Carlo, en las dos obras citadas, corresponde al 8 de Julio de 1755; En la relación del 7 de Noviembre de 1724: "Hizo un Certamen poético y dió un vexamen. Para exercitarse en todo género de buenas letras, hizo en la susodicha Academia, la vez que le tocó, un certamen poético en honra del Nacimiento de Nuestro Señor, y dió un vexamen académico". 
otras artes, para que confiriendo entre sí y discutiendo sus problemas, saliesen cada día más prácticos y sabios (pág.87).

\section{Eguiara y los origenes de la "Ilustración católica" en Nueva España}

Entramos, para casi finalizar, en un concepto contradictorio de la historia de la cultura: el de "Ilustración católica", que José Carlos Chiaramonte ha definido, mirando a Hispanoamérica, como "ese paradójico movimiento intelectual que se abre entusiásticamente a la seducción del 'espíritu del siglo' pero, al mismo tiempo, salvaguarda y reafirma su adhesión a los dogmas de la Iglesia" ${ }^{14}$. Por una parte, nos conduce a ejemplos del pensamiento europeo y, por otra, masivamente, a nombres del pensamiento hispanoamericano actuante, por ejemplo, en los jesuitas expulsos de España y América a partir de 1767.

Eguiara asume en su texto polémico, como hemos visto, las posiciones de Feijoo, pero asume sobre todo las posiciones polémicas de defensa de América que jesuitas como Francisco Javier Clavijero desarrollarán, en su polémica con Cornelius de Pauw, a partir de 1780.

Globalmente, como hemos dicho, anticipa posiciones "indigenistas" de Clavijero, o Pedro José Márquez, jesuitas expulsos cuya obra anima el pensamiento americanista en la Italia del siglo XVIII. $Y$ anima un debate de la Ilustración que de nuevo, aquí, no puedo más que señalar brevemente.

Una línea a recorrer es la relación de Eguiara con los jesuitas de Nueva España en la que posiblemente encontremos una determinación previa del pensamiento del ilustre polemista, antes de que éstos, tras su expulsión, llenaran de voces americanas el pensamiento europeo. A principios de nuestro siglo, deduciéndolo de sus pareceres y aprobaciones de obras de jesuitas -el mencionado Vicente López lo era- José Toribio Medina hacia una deducción que anima esta perspectiva, comentando los pareceres aprobatorios de obras que Eguiara debió informar, citando uno del 12 de Enero de 1750 que comenta así:

${ }^{41}$ Prólogo a Pensamiento de la Ilustración. Economía y sociedad iberoamericanas en el siglo XVIII, Caracas, Ayacucho, 1979, págs. XVIII-XIX. 
Lazcano. Opusculum theophilosophicum. El parecer de Eguiara está escrito en latín, como toda la obra. Lazeano fue también un jesuita célebre. Estas repetidas muestras de confianza que le dispensaba la Compañía de Jesús tratándose de sus miembros más conspicuos, denotan bien a las claras los buenos términos en que Eguiara se hallaba con ella y el aprecio que se tenía de sus prendas ${ }^{42}$,

e insiste a continuación Toribio Medina en otros pareceres dedicados a otros jesuitas.

En cualquier caso, si es conocido el pensamiento americano de los jesuitas expulsos una vez en Europa, parece un espacio a indagar los orígenes de este pensamiento tras la expulsión, y la clave de Eguiara en su relación con éstos parece un camino a recorrer.

También podríamos señalar, con la prudencia que un artículo nos exige, todo lo que de reivindicación nacional tiene el texto de Eguiara, y leerlo, como perspectiva que estaba empezando a cuajar en el ambiente en la determinación del pensamiento ilustrado en América, en la dirección en que el jesuita Juan Pablo Viscardo escribió en 1792 su Carta a los espanoles americanos -título, por otra parte, que tiene resonancias de Feijoo- y que Francisco Miranda convirtió en texto esencial de la Independencia. Pero complejos problemas historiográficos nos impiden emitir ninguna opinión sobre esto por el momento y nos invitan a concluir.

\section{Reivindicación de Eguiara y del deán Martí}

Las notas anteriores no son más que una entrada en un ámbito cultural, y un momento del mismo, que nos deja con más cuestiones abiertas que cerradas, con más motivos a indagar que concluidos, con más incertidumbre que cuando comenzamos a escribirlas.

De ellas se desprende sobre todo una cuestión que el espacio de un artículo y las referencias que en él caben, con seguridad, no pueden dejar resuelta, y concierne al sentido global de la llustración en Nueva España. Al citar los materiales esenciales de Gerbi anotábamos que la

${ }^{42}$ Toribio Medina, op. cit, vol. I, pág. CCXLIII. 
réplica de Eguiara a Martí antedataba la polémica del Nuevo Mundo, central en el pensamiento ilustrado y esencial hasta nuestros días.

Por otra parte, para concluir, debemos recordar la perspectiva crítica que tiende a situar la Ilustración en América en el pensamiento económico y político, y posteriormente en el independentista, y sitúa el momento principal de la evolución de las ideas ilustradas tras la primera mitad del siglo XVIII.

La consistencia del trabajo de Eguiara, la razón enarbolada para centrar las bases de su elaboración, sus referencias culturales que abren el camino a lo que la historiografía llamó Ilustración católica informada por los jesuitas, antes de su expulsión y, sobre todo, en su exilio italiano, son datos que aquí hemos querido señalar, y que en todo caso abren una perspectiva de contraste e investigación que se debe recorrer.

Bien sea para situar a Eguiara y Eguren fuera del espacio menor de la cita breve y bibliográfica, o bien sea -podría ser en último extremo nuestro caso- para dar una nueva dimensión al huraño "decanus alonensis" que, sin querer, provocó un enfado descomunal entre los intelectuales de América, un enfado de los receptores cuando el causante ya había muerto $y$, en este caso, su victoria habría sido, tras la ofensa, provocar una línea de respuesta que significa una posibilidad para que nosotros nos encontremos con un trazo consistente de la polémica preilustrada en América. 